
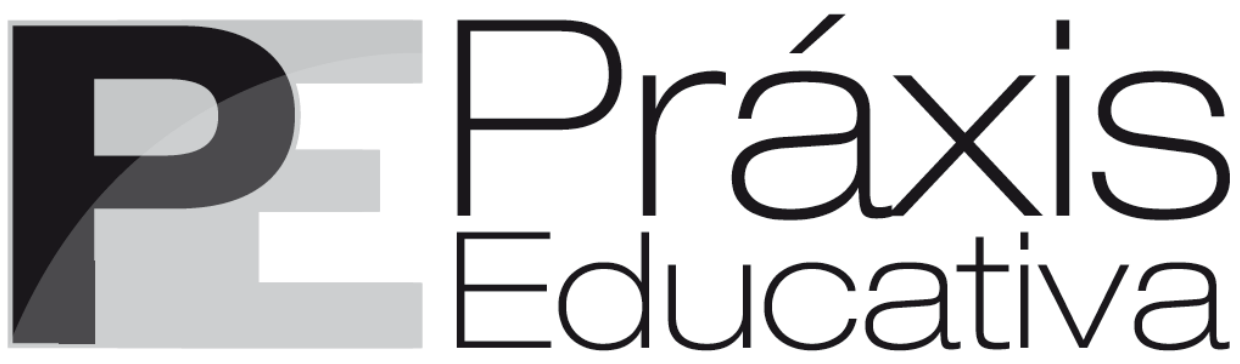

ISSN 1809-4031

elSSN 1809-4309

https://doi.org/10.5212/PraxEduc.v.15.14819.039

\title{
A defesa pela "liberdade de escolha" fortalecendo uma rede empresarial: o homeschooling brasileiro
}

\section{The defense for "freedom of choice" strengthening a business network: Brazilian homeschooling}

\section{La defensa de la "libertad de elección" fortaleciendo una red empresarial: la homeschooling brasileña}

\author{
Stephane Silva de Araujo* \\ iD https://orcid.org/0000-0003-0730-7139 \\ Maria Cecilia Lorea Leite ${ }^{* *}$ \\ (iD) https:/ / orcid.org/0000-0002-9197-2299
}

\begin{abstract}
Resumo: O homeschooling vem ganhando notoriedade no cenário nacional nos últimos anos. Considerando tal peculiaridade, este estudo exploratório concentrou-se em identificar, a partir da campanha brasileira "EducAÇÃO Domiciliar - Direito Já", liderada pela Associação Nacional de Educação Domiciliar (ANED), que agentes individuais ou coletivos se caracterizam como apoiadores daquela e que tipos de serviços oferecem à população. Constatou-se a existência de uma "rede" pautada por interesses conservadores, predominando em seus discursos um viés mercantil, seletivo e contrário à docência e à escolarização. Observou-se, ainda, a atuação concomitante dos sujeitos em diversas plataformas, as quais oferecem guias pedagógicos, cursos e certificações com elevados custos, evidenciando, portanto, o público a que se destinam.
\end{abstract}

Palavras-chave: Homeschooling. Rede empresarial. Direito à educação.

Abstract: Homeschooling has gained notoriety on the national scene in recent years. Considering this peculiarity, this exploratory study focused on identifying, from the Brazilian campaign "Home Education Immediate Right", led by the National Association of Home Education (Associação Nacional de Educação Domiciliar - ANED), which individual or collective agents are characterized as supporters of that and what types of services they offer to the population. The existence of a "network" based on conservative interests was verified, predominating in their discourses a mercantile, selective and contrary to teaching and schooling bias. It was also observed the concomitant performance of the subjects in several platforms, which offer

\footnotetext{
* Doutoranda em Educação pelo Programa de Pós-Graduação em Educação (PPGE) da Universidade Federal de Pelotas (UFPel). Mestra em Educação pela UFPel. E-mail: <stephaneslv@gmail.com>.

** Professora da UFPel. Doutora em Educação pela Universidade Federal do Rio Grande do Sul (UFRGS). E-mail: $<$ mclleite@gmail.com>.
} 
A defesa pela "liberdade de escolha" fortalecendo uma rede empresarial: o homeschooling brasileiro

pedagogical guides, courses and certifications with very high costs, thus highlighting the intended target audience.

Keywords: Homeschooling. Business network. Right to education.

Resumen: La homeschooling ha venido ganando notoriedad en el escenario nacional en los últimos años. Considerando tal peculiaridad, este estudio exploratorio se concentró en identificar, a partir de la campaña brasileña "Educación Domiciliaria - Derecho Ya", liderada por la Asociación Nacional de Educación Domiciliaria (Associação Nacional de Educação Domiciliar - ANED), qué agentes individuales o colectivos se caracterizan como partidarios de aquélla y qué tipos de servicios ofrecen a la población. Se constató la existencia de una "red" pautada en intereses conservadores, predominando en sus discursos un sesgo mercantil, selectivo y contrario a la docencia y a la escolarización. También se observó la actuación simultánea de los sujetos en diversas plataformas, los cuales ofrecen guías pedagógicas, cursos y certificaciones con costos elevados, evidenciando, por lo tanto, el público al que se destinan.

Palabras clave: Homeschooling. Red empresarial. Derecho a la educación.

\section{A confluência de interesses empresariais em torno de uma campanha em prol da educação domiciliar no Brasil - apontamentos iniciais}

A retórica da crise educacional tem potencializado a emergência de respostas privadas, supostamente promissoras e exitosas, frente ao presumido declínio da educação pública. Nesse contexto, a reunião de um grupo de pais e de mães interessados em praticar a Educação Domiciliar (ED), no Brasil, em torno de uma Associação Nacional, fortaleceu seu movimento de defesa. Experiências consideradas bem-sucedidas, segundo a perspectiva de seus praticantes, propiciaram a emergência de métodos pedagógicos entendidos como replicáveis. O suposto êxito da ED fundamenta o comércio dos cases de algumas famílias.

Um sem-fim de "faça você mesmo", "como alfabetizar seu filho em $x x$ passos", "como otimizar sua leitura", entre outros cursos, apostilas e instituições certificadoras, movimentam um verdadeiro comércio didático-pedagógico na internet. Entre crônicas e textos de apoio à ED e de crítica à docência como pressuposto de escolarização e construção do conhecimento científico, consolida-se um e-commerce bem estruturado, com práticas voltadas inclusive à assessoria online em aplicativos de smartphone.

Neste artigo, ao focalizarmos a campanha brasileira "EducAÇÃO Domiciliar - Direito Já" (ANED, 2019b, n.p.), liderada pela Associação Nacional de Educação Domiciliar (ANED), identificamos quem são os agentes individuais ou coletivos que se caracterizam como seus apoiadores, bem como que tipos de serviços que oferecem à população e como se dão suas relações na rede empresarial ${ }^{1}$ que constituíram. O debate sobre a temática é adensado, ainda, a partir da problematização quanto à oposição entre o escopo da política de ED e a perspectiva constitucional de direito à educação.

\footnotetext{
${ }^{1}$ Salientamos que não se trata de rede empresarial voltada à discussão de parâmetros e políticas educacionais, bem como não possui capilaridade semelhante à rede formada pelo “Todos pela Educação", por exemplo. Trata-se, sim, de rede de colaboração entre sujeitos individuais e coletivos que se pauta pelo intercâmbio profissional e pela defesa do direito de liberdade de escolha dos pais quanto à forma de educar seus filhos. Nesse sentido, inaugura um nicho mercantil de serviços e de produtos a ofertar às famílias que intentam executar a Educação Domiciliar. Utilizamos a expressão "rede empresarial" para denotar que algumas entidades se envolvem em campanha que defende a regularização do homeschool no Brasil, mas que têm por interesse a profusão dos próprios negócios ofertados em diferentes plataformas virtuais. A atuação em rede, nesse cenário, garante tanto a cooperação, como o controle discursivo acerca do que é proposto em torno da ED e de modo mais relevante o retorno financeiro frente ao comércio do serviço educacional que prestam.
}

Práxis Educativa, Ponta Grossa, v. 15, e2014819, p. 1-20, 2020 
A análise exploratória desenvolvida nas plataformas digitais (sites e redes sociais) dos apoiadores da referida campanha denotou o estabelecimento de uma rede empresarial na qual diferentes sujeitos inclinam suas práticas à oferta de produtos pedagógicos às famílias homeschoolers. Nessa esteira, valemo-nos de Castells (2005), para quem a consolidação de redes se dá a partir da evolução das tecnologias de comunicação e informação, exatamente como percebemos entre os parceiros analisados.

No caso específico do homeschooling, compreendemos que o novo paradigma tecnológico atua duplamente, tanto no sentido de elevar as possibilidades de desenvolvimento da prática de educação a distância com a evolução e maior acesso à internet, quanto pela proximidade que institui entre diferentes atores que passam a defender uma mesma pauta a partir de práticas discursivas e de atuação semelhantes. Particularmente em relação aos parceiros focalizados nesta investigação, percebemos que desempenham práticas similares de defesa da educação domiciliar e encorajamento e responsabilização dos pais, inicialmente, e consequente oferta dos meios necessários para desenvolvê-la, a saber: manuais, cursos completos e certificações.

Não obstante, verificamos o reforço a uma prática seletiva do direito de alguns, poucos terão o acesso necessário e irrestrito às novas tecnologias para produzir a partir daí meios para uma educação de qualidade. Assim, a seletividade empreendida pelas medidas em defesa do bomeschooling, aqui observadas, manifesta sutil enfrentamento à Constituição Federal, que imputa caráter universal e de obrigatoriedade de acesso à Educação Básica. De tal modo, insta contemplar também as possibilidades de incidência de efeitos nocivos à efetivação da cidadania e, por conseguinte, à materialização da democracia em um país que possui histórico recente de redemocratização.

A defesa em torno do direito familiar à escolha sobre como educar seus filhos traveste a emergência de um mercado consolidado em prol da comercialização de produtos voltados à ED. Nos ambientes virtuais observados na investigação realizada, constatou-se que se tornou corriqueira a presença de links voltados a lojas que tratam do direito à educação como uma mercadoria ao alcance de poucos. Portanto, a consolidação de uma rede empresarial voltada ao comércio de ferramentas pedagógicas para a produção do conhecimento junto aos filhos de famílias abastadas constitui-se foco central deste artigo.

Tal fenômeno foi apontado anteriormente por Gaither (2008, 2017), em importante estudo sobre a história do homeschool no contexto norte-americano. A propósito, Oliveira e Barbosa (2017), reportando-se a contribuições do historiador da educação, abordadas na obra mencionada, no que concerne ao negócio do ensino domiciliar, asseveram que

[...] todo o crescimento, expansão e modernização do movimento homeschool transformouse em um grande negócio, com um forte mercado que mobiliza editoras, empresas que atuam em congressos (que atendem milhares de pessoas), venda de materiais na internet, entre outros, proporcionando-lhes grandes lucros [...]. (OLIVEIRA; BARBOSA, 2017, p. 205).

Nesse sentido, questionamos: O que está em jogo é, de fato, apenas a liberdade de escolha dos pais? Ou estamos diante de um problema de segregação de uma parcela da população, de uma política que deve atender a todos, como a educacional? Ou, ainda, estamos diante da defesa de um interesse pura e simplesmente mercantil? Haja vista o considerável investimento financeiro privado em oportunidades ditas mais bem organizadas e produzidas do que as orientadas pelo Estado, várias indagações podem ser suscitadas. Entre elas, a discussão em prol de uma modalidade educativa que prega maior individualização no processo de ensino-aprendizagem; e o debate sobre os impactos que a democracia pode sofrer a partir do "novo" tipo de socialização que a ED impõe, diversa do espaço plural e público, constitucionalmente endereçado à escola. 
A materialização dessa política inauguraria uma miríade de efeitos que acentuam a diferença entre crianças e adolescentes que não apresentam histórico equivalente de acesso às políticas sociais. Hamlin (2019), ao analisar a aquisição de capital cultural por crianças em idade escolar, matriculadas na rede de ensino e praticantes da educação domiciliar, alega que, embora haja um acentuado declínio de experiências que apenas o convívio escolar possibilitaria, as crianças que estudam em casa desenvolvem um rol acentuado de práticas que elevam seu capital cultural, devido ao incremente de atividades nesse sentido. Dessa maneira, temos um indicativo referente à discrepância entre os serviços postos à disposição da comunidade em idade escolar que frequenta a escola e a que acessa seus conteúdos de modo privado, reforçando, assim, diferenças pessoais que potencializarão a meritocracia e a consolidação de uma sociedade pautada pelo valor de cada sujeito.

Assim, de modo a refutar tal entendimento, reportamo-nos aos argumentos de Vasconcelos e Boto (2020) no que diz respeito à essencialidade do convívio escolar para a construção de pressupostos éticos e cívicos, orientados pela diversidade. Para as autoras:

A escola, então, supõe um aprendizado da ética e da civilidade. Ao serem educadas apenas na casa, as crianças não serão suficientemente preparadas para ingressar no mundo público e não serão confrontadas com a diversidade social. A família constitui uma totalidade relativamente homogênea; a escola lida necessariamente com a pluralidade. É fundamental frequentar a escola para aprender a reconhecer, a respeitar e, por vezes, a enfrentar aquilo que é diferente. (VASCONCELOS; BOTO, 2020, p. 15).

Na mesma perspectiva, Cury (2019) focaliza a convivência no espaço escolar:

A escolaridade traz consigo o campo da convivência. Convivência que reabre uma nova tensão: os diferentes se encontram em um espaço comum a fim de conhecerem e praticarem 'as regras do jogo'. Os diferentes se encontram para que haja um reconhecimento recíproco da igualdade, da igualdade essencial entre todos os seres humanos. Os diferentes se encontram para, em base de igualdade, reconhecer e respeitar as diferenças. É nesse ir e vir de conhecimento comum, de aprendizado das regras do jogo, da consciência da igualdade e do reconhecimento do outro como igual e diferente que se efetiva a "dignidade da pessoa humana", princípio de nossa Constituição. (CURY, 2019, p. 6).

Com base nesses argumentos, Cury reforça a relevância do espaço comum, o reconhecimento mútuo da igualdade e da diferença, bem como do necessário respeito às diferenças. Nesses termos, o autor destaca, ainda, o princípio constitucional da dignidade da pessoa humana, considerado um direito fundamental crucial entre os direitos fundamentais consagrados em nossa Constituição Federal de $1988^{2}$. Torna-se ressonante, por conseguinte, o posicionamento de Casanova e Ferreira (2020), com quem concordamos não se tratar de liberdade de escolha, mas, sim, da concepção de sujeitos que confrontam preceitos constitucionais.

Consideração reforçada pela compreensão de Cury ao tratar da Educação Básica como um direito de todos. Para além da aquisição de valores comuns que aperfeiçoam a construção de um espaço cidadão e democrático, há, também, o desenvolvimento da humanidade como um todo, conforme aponta o autor.

A ligação entre a dimensão básica e o conceito de comum, na educação, carrega um sentido próprio. Comum opõe-se a uma educação específica (do tipo ensino profissional), de classe (que constitua um privilégio) ou mesmo que carregue algum diferencial mesmo que lícito (escola confessional). A noção de comum associada à educação básica é um direito (em oposição a privilégio) e busca, em sua abertura universal, o aprendizado de saberes válidos para toda e qualquer pessoa, responde a

2 Artigo $1^{\circ}$, inciso III, da Constituição Federal de 1988 (BRASIL, 1988).

Práxis Educativa, Ponta Grossa, v. 15, e2014819, p. 1-20, 2020

Disponível em: <http://www.revistas2.uepg.br/index.php/praxiseducativa> 
necessidades educativas do desenvolvimento humano como um patrimônio cultural. $\mathrm{O}$ "comum" vai mais além de um "para todos", reportando-se a conhecimentos científicos, à igualdade, à democracia, à cidadania e aos direitos humanos (Teixeira, 1994). (CURY, 2008, p. 300).

Está reforçado, portanto, o compromisso precípuo da instituição escolar para com a formação de sujeitos que exercitem seus direitos e atuem orientados por seus deveres na construção de uma sociedade mais justa e igualitária, encurtando as diferenças entre os sujeitos. Compreendemos que tal característica estaria em suspenso no caso da educação domiciliar, uma vez que seus praticantes advogam pelo fim da regulação do processo educacional e pelo total desvencilhamento das premissas escolares, fortalecendo um espectro de invisibilidade das diferenças e enaltecendo, por fim, a meritocracia.

Assim, tomamos como premissa, neste artigo, observar a partir de uma campanha pró-ED quem são os sujeitos que a defendem, que tipo de serviços prestam à sociedade e o que os une de fato. Fundamentamos essa perspectiva em Peroni, Caetano e Lima (2017), pois salientam a relevância de pesquisas que focalizem o desenho, os sujeitos e o conteúdo das propostas de reformas educacionais. Em especial no tocante à ED, compreendemos a pertinência de tal posicionamento tomando por base o atual processo de desescolarização defendido pelos agentes aqui apresentados. Faz-se necessário que observemos essa situação que nos parece negar, ou pelo menos reduzir fortemente, o exercício de ações democráticas desenvolvido no contexto escolar.

Para Oliveira e Barbosa (2017), estamos tratando do posicionamento antiestatal de grupos anarquistas, liberais individualistas e religiosos fundamentalistas contrários à compulsoriedade da educação escolar". Assim sendo, pelo menos duas questões fundamentam a defesa pela ED: "Se as famílias são diferentes em sua moral, crença e valores, como oferecer um único tipo de ensino? Que direitos tem o Estado de promover um ensino com embasamentos distintos dos apregoados pelas famílias?” (OLIVEIRA; BARBOSA, 2017, p. 198).

Faz-se inevitável salientar, por um lado, que a crítica veiculada nesse trabalho não se dirige particularmente às instituições ou aos sujeitos focalizados. Por outro lado, é importante explicitar que o debate em foco coaduna com o posicionamento de Peroni (2018), ao defender que o Estado seja o responsável direto pela materialização da política educacional, tendo em vista seu caráter público e sua função central na construção e na consolidação da democracia. Esse entendimento é reforçado por Cury (2013) ao observar que o caráter público, tanto do Estado quanto da política educacional, atribui àquele a responsabilidade pela materialização da política pública. Espera-se, por consequência, que a oferta de um serviço educacional público para todos produza a redução das discrepâncias entre os sujeitos, por vezes reforçadas pelo acesso facilitado ao capital.

Assim, o direito à educação se liga, intrinsecamente, à função pública do Estado na medida em que só ele pode estender universalmente a escola para todos e assim atender o conjunto dos cidadãos com imparcialidade de modo a fazer cumprir os grandes objetivos da democracia e da justiça. Daí as obrigações do Estado quanto ao financiamento e qualificação deste direito. Só ele pode propiciar condições que, na oferta do ensino, vão equalizando novas oportunidades para grupos menos aquinhoados de capital cultural, com insumos diferenciados. (CURY, 2013, p. 202).

\footnotetext{
${ }^{3}$ Os autores, ao analisarem a perspectiva teórica de Ludwig Heinrich Edler von Mises, Milton Friedman e Friedrich August von Hayek, precursores do neoliberalismo, observam que uma das “[...] convergências entre eles se encontra na rejeição à educação compulsória. Eles não são contra, em princípio, a que o indivíduo seja obrigado a educar-se. Entretanto, insurgem-se contra a ideia de que o provedor único dessa educação seja o Estado" (OLIVEIRA; BARBOSA, 2017, p. 198).
} 
Também nos auxilia na busca de compreensão quanto à concepção estatal envolta na defesa pelo bomeschooling no Brasil, a fala Freitas (2018) acerca da necessidade que políticas reformistas como esta têm de afastar o Estado de suas responsabilidades, justificando, desse modo, os processos de privatização das políticas públicas, sobretudo as de cunho social, tais como a educação. Nesse sentido, ao afirmar a maior privatização da educação a partir das políticas reformistas adotadas globalmente desde meados dos anos 1990, o autor alerta que "[...] a educação, vista como um 'serviço' que se adquire, e não mais como um direito, deve ser afastada do Estado, o que justifica a sua privatização" (FREITAS, 2018, p. 29) Assim, compreendemos de modo mais claro a defesa dos pais homeschoolers brasileiros que lutam pelo direito de escolha e não pelo direito à educação. Advogam, portanto, a possibilidade de exercer a educação domiciliar sem regulação estatal, já que, como afirma Freitas (2018, p. 32), qualquer modalidade de intervenção "[...] destinada a eliminar essa diferença é vista como algo indevido que desestimula a busca pelo mérito pessoal, sendo ainda uma injustiça com aquele que se esforçou".

Resta indispensável, nesse cenário, focalizar a instituição que se apresenta como o principal grupo pró-homeschooling no Brasil: a ANED. Posteriormente, apresentaremos os sujeitos individuais e coletivos identificados como apoiadores da Campanha "EducAÇÃO Domiciliar - Direito Já", liderada pela referida Associação, a partir dos materiais disponíveis em suas plataformas digitais, sobretudo com enfoque voltado aos produtos ofertados que evidenciam a consolidação de um mercado pedagógico e a seletividade fundante da ED, no Brasil. Por fim, destacaremos a constituição de uma rede formada por tais sujeitos em prol da regulamentação da ED no país, considerando seus interesses religiosos e financeiros.

\section{O protagonismo da Associação Nacional de Educação Domiciliar no Brasil}

Neste estudo, evidenciamos o papel central que vem sendo desenvolvido pela ANED no Brasil, nos últimos anos, assim como Casanova e Ferreira (2020) também apontam. A referida Associação apresenta-se como uma instituição sem fins lucrativos, criada em 2010, com a finalidade de congregar e amparar as famílias que lutam pelo direito de escolher como se dará a educação de seus filhos; enfim, pleiteiam o direito de exercer a ED no Brasil. Desde então, a instituição demonstra considerável capilaridade e poder de atuação junto aos pais e mães homeschoolers, mas também aos três Poderes: Judiciário, Legislativo e Executivo (ANED, 2019a, n.p.).

Entre as atividades consideradas "destaques" pela ANED, podemos citar: a consultoria jurídica às famílias homeschoolers, sobretudo para as já denunciadas; a organização de eventos nacionais e internacionais sobre ED, assim como de audiências públicas junto a órgãos do Legislativo e Executivo; a produção e a divulgação de materiais informativos e campanhas em defesa do homeschooling; a atuação junto ao Supremo Tribunal Federal, enquanto Amicus Curiae; e o apoio à produção acadêmica pró-bomeschooling (ANED, 2019c, n.p.).

Em que pese não tenha sido citada diretamente como "atividade destaque", a análise exploratória do site, das redes sociais e de veículos de comunicação evidencia que uma de suas ações centrais é o lobby e consequente assessoria legislativa junto a parlamentares das esferas estadual e municipal. A partir da atuação da ANED, estados, como o Rio Grande do Sul e Santa Catariana, e municípios, como São Paulo/SP e Vitória/ES, vem discutindo e regulamentando o exercício de tal modalidade educativa.

A Associação demonstra bastante cautela ao posicionar-se e pronunciar um discurso acerca da pertinência e das vantagens da ED, sem que seja necessário, para tanto, menosprezar outras formas de ensino. Por um lado, não há menções depreciativas ao processo de escolarização ou mesmo aos docentes. A temática é apresentada de modo a angariar adeptos à luta pelo direito de 
escolha das familias homeschoolers. A ANED problematiza, de outro lado, a compulsoriedade do sistema educacional brasileiro, frente aos baixos índices de aprovação em exames de larga escala, por exemplo.

Para tanto, a Associação disponibiliza em sua plataforma digital materiais elucidativos, assim como vídeos nos quais a modalidade é apresentada e mitos são desconstruídos. Percebemos a produção discursiva a partir da antítese do que a modalidade educativa denota ser; desse modo, há uma preocupação latente em romper com a retórica do senso comum para, a partir daí, criar o significado positivo da ED, fundado na responsabilidade total dos pais sobre seus filhos e consequente direito de escolha acerca da educação mais adequada para eles.

No que concerne ao Poder Legislativo, há forte atuação junto às bancadas parlamentares do Congresso Nacional. Desde, pelo menos, 1994, a temática é discutida sem muitos avanços na Câmara dos Deputados e no Senado Federal, conforme apontam Vasconcelos e Boto (2020). Todavia, a ANED demonstra estar sempre presente, respaldando, nesse período, a apresentação de projetos de lei (ANED, 2019d, n.p.).

Não obstante, é a partir de 2015 que a própria Associação denota a maior visibilidade da temática e de sua atuação, quando lhe foi autorizado o ingresso em uma ação judicial que tramitava no STF, na qualidade de Amicus Curiae. A discussão gerou, à época, a possibilidade de suspensão dos processos judiciais em tramitação contra famílias homeschoolers que, em sua maioria, respondiam criminalmente por abandono intelectual (ANED, 2019e, n.p.).

Mesmo assim, a Associação afirma que o crescimento do número de adeptos à ED tem sido vertiginoso no Brasil e estaria relacionado a uma espécie de transversalidade de políticas públicas educacionais; dessa maneira, credita-se tal elevação também à consolidação de provas nacionais de certificação de conhecimentos, como o Exame Nacional para Certificação de Competências de Jovens e Adultos (ENCCEJA) e o Exame Nacional do Ensino Médio (ENEM). "A Educação Domiciliar no Brasil, é um fenômeno consolidado e imparável, tendo crescido mais de 2000\% nos últimos 8 anos. Saltando de cerca de 360 famílias em 2011, para 7500 famílias educadoras, em 2018, com cerca de 15000 estudantes, entre quatro e dezessete anos" (ANED, 2019a, n.p.).

Todavia, conforme já referimos, a ANED não possui apenas uma frente de atuação. Diante do seu protagonismo, passou a atuar mais fortemente junto aos Poderes Executivo e Legislativo, tendo em vista que o julgado do STF apresentou, como direção final, a produção de uma legislação específica que regulamentasse a matéria. Nesse sentido, núcleos regionais da Associação foram sendo fortalecidos de modo a tornar visível a demanda das famílias, assim como os resultados que estas vêm conquistando com a educação domiciliar de seus filhos.

Ainda, não se trata de um protagonismo apenas nacional, pois a Associação tem atuação internacional por meio de parcerias com instituições congêneres, entre as quais: a Home School Legal Defense Association (HSLDA). Nessa perspectiva, a investigação possibilitou a compreensão de que além de ser uma rede empresarial, uma vez que a relação entre os apoiadores da campanha da ANED tem como pano de fundo a comercialização do conhecimento, também se estabelece uma rede global, pois reúne parceiros internacionais, os quais definem, mesmo que tacitamente, linhas básicas de atuação. Compreendemos tal indicativo a partir de Castells (2005, p. 18) ao afirmar que a "[...] sociedade em rede é global, é baseada em redes globais. Então, a sua lógica chega a países de todo o planeta e difunde-se por meio do poder integrado nas redes globais de capital, bens, serviços, comunicação, informação, ciência e tecnologia"; parte dessa rede se dá, por conseguinte, a partir da difusão e do compartilhamento de expertise globalmente. 
No que concerne a esta investigação, essa afirmação encontra esteio na prática da líder da campanha, a ANED, que traduz materiais e pesquisas da HSLDA para a língua portuguesa, estabelecendo a lógica de educação domiciliar americana. Percebemos, ainda, o direcionamento para sites de outras instituições norte-americanas, o que fortalece nossa concepção quanto à seletividade do público atendido por essa proposta de homeschooling, de onde emerge um projeto de sociedade em rede bastante peculiar e restrita a poucos (ANED, 2019f, n.p.).

De toda sorte, o campo que apresentou maior aderência à proposta da ANED, sem, no entanto, atender completamente a sua demanda, foi o Poder Executivo. De acordo com a Associação, a temática vem ganhando espaço na esfera federal, tendo sido bem recebida pelo atual Presidente da República (ANED, 2019g, n.p.) Este a assumiu, inclusive, como uma das metas prioritárias para os 100 primeiros dias de governo, e dispôs-se a propor a sua regulamentação, a partir da apresentação de uma Medida Provisória. Todavia, prevendo o possível desgaste que a agenda ocasionaria, ela foi deslocada do Ministério da Educação para o Ministério da Mulher, da Família e dos Direitos Humanos, por tratar-se, segundo a interpretação do Governo, de uma pauta familiar. Na esteira dessa alteração, a proposta principal é de mudança de artigos do Estatuto da Criança e do Adolescente (ECA) e de forma coadjuvante da Lei de Diretrizes e Bases da Educação Nacional (LDBEN).

Nessa esteira, Casanova e Ferreira (2020, p. 7) percebem que a defesa pela ED no Brasil se amplia com a referida aproximação e fortalece "[...] alguns discursos de perspectiva de mercantilização, gerencialismo da educação e mecanismos para o âmbito individual e não para o coletivo". Tal referência encontra materialidade em nosso artigo, por meio da focalização das entidades que defendem a modalidade no país e, que claramente, apresentam interesse financeiro no direito de liberdade de escolha para ensinar em casa. Apesar disso, a proposta de regulamentação da ED apresentada ao Congresso Nacional não agradou as famílias homeschoolers. Em primeiro lugar, elas aguardavam que a pauta fosse apresentada via Medida Provisória e o foi por meio de um Projeto de Lei, sabidamente mais moroso e com a necessidade de maior atuação junto aos congressistas. Em segundo lugar, torna-se crível, a partir das evidências coletadas nas plataformas digitais, que a defesa pelo direito de escolha dos pais está diretamente atrelada ao fim da compulsoriedade do direito à Educação, bem como a nenhum tipo de regulação por parte do Estado.

Entretanto, é a partir da divulgação de seu desempenho incisivo em instituições, como Comissões de Educação das Casas Legislativas, Ministério da Educação e Conselho Nacional de Educação, que a ANED reforça sua capilaridade e enfatiza a necessidade de apoio à causa, a partir da adesão financeira de novas famílias à Associação, ao custo de $\mathrm{R} \$ 360,00$ anuais (ANED, 2019h, n.p.) Afirma, para tanto, que organiza grupos locais para que pais e mães não se sintam sós nesta árdua tarefa de educar os filhos em casa, oferecendo o serviço de orientação e de acolhimento dessas famílias e, em breve, um "clube de descontos e vantagens". Consideramos, portanto, a existência de um viés econômico que circunda a temática. Entretanto, resta claro que, para além da anuidade, não há a cobrança de demais taxas para utilização do espaço virtual da ANED.

Outro elemento que evidencia a perspectiva financeira da proposta, bem como seu viés segregacionista, pode ser encontrado no quesito "perguntas e respostas", constante no site da associação (ANED, 2019j, n.p.). Em que pese a ANED afirme que a ED não trata de uma agenda elitista e que grande parte das famílias homeschoolers são de classe média e possuem elevado

\footnotetext{
${ }^{4}$ De acordo com a Associação: "Num futuro breve a ANED deverá lançar um Clube de Benefícios que, como o próprio nome já diz, trará benefícios como descontos em produtos e serviços para as Famílias Associadas Contribuintes, incentivando o desenvolvimento e facilitando aos pais a missão de educarem seus filhos" (ANED, 2019i, n.p.).
} 
investimento na área educacional em instituições privadas, ao tratar do interesse de famílias menos abastadas, identificadas como "desestruturadas ou economicamente miseráveis" pela ED, é do seguinte modo que se posiciona: "A experiência de outras nações mostra que famílias desestruturadas socialmente, vulneráveis ou em condição de miséria não se interessam pela educação domiciliar. Pelo contrário, preferem a escola em tempo integral" (ANED, 2019j, n.p.).

Casanova e Ferreira (2020, p. 8) identificam ainda, nos discursos da ANED, três pontos que evidenciam a relação entre mercantilização e educação domiciliar: "ênfase nas provas padronizadas, o nicho de mercado que se abre e o empreendedorismo". Em nossa investigação, evidenciamos pelo menos dois desses pontos frente à ascendência de famílias empreendedoras, que ofertam sua expertise na orientação de novas famílias bomeschoolers como uma mercadoria, inaugurando, assim, o mercado de materiais e de manuais de ensino e de autoajuda. Ao estabeleceram um intercâmbio entre si, fortalecem uma rede de apoio que referenda aos usuários o trabalho dos colegas, disponível para consumo em seus respectivos sites e apps.

Embora a colocação da ANED tenha sido infeliz e indelicada, e haja o reforço à perspectiva mercantil e segregacionista nessa proposta, Vasconcelos (2017), assim como outros autores, reforça-a ao afirmar que se pode

[...] supor que os pretensos adeptos do bomeschooling no Brasil, provavelmente, não seriam oriundos da escola pública, mas, sim, da escola privada. É nela que estariam os pais com condições econômicas, culturais e sociais suficientes para se encarregar da educação dos filhos, preparando-os não só para realizar as avaliações decorrentes das regulamentações que, normalmente, são exigidas para a prática do bomeschooling - como forma de manter um mecanismo de controle por parte do estado -, mas também para ministrar e supervisionar aulas e lições cotidianas, com disponibilidade para que um membro da família se dedique a essa tarefa, deixando o mercado de trabalho. (VASCONCELOS, 2017, p. 131).

Ainda, concordamos com Lima (2018) que, ao analisar a influência de tendências neoconservadoras na pauta educacional brasileira e suas implicações para a democracia, pondera que posicionamentos semelhantes aos da ANED estabelecem, "[...] grosso modo, um projeto educativo (certamente vinculado a um projeto societário) que objetiva a manutenção das estruturas de opressão e exclusão da diversidade e a manutenção das desigualdades sociais, sob a prerrogativa da conservação de valores e costumes morais tradicionais" (LIMA, 2018, p. 130).

De igual modo, consideramos que a consolidação da perspectiva político-econômica neoliberal oferece os arranjos necessários à ascensão daquilo que se apresenta como uma "nova modalidade educativa", pois, conforme Freitas (2018, p. 31), “[...] o neoliberalismo olha para a educação a partir de sua concepção de sociedade baseada em um livre mercado cuja própria lógica produz o avanço social com qualidade, depurando a ineficiência através da concorrência". Nesse sentido, observamos a proliferação de um nicho mercantil composto por instituições que oferecem produtos aos praticantes do homeschooling, originando o que percebemos ser uma rede empresarial. Todavia, embora os sujeitos individuais e coletivos envolvidos na questão sejam parceiros em ações que os unem, resta claro que atuam com base na comercialização de seus serviços, competindo entre si, no que se refere à mercantilização pedagógica.

Em que pese Castells (2005) se refira a conglomerados de empresas, ao tratar do estabelecimento de uma economia em rede, pensamos que nossa investigação encontra esteio em sua concepção, pois, conforme abordaremos na sequência, os apoiadores da campanha "EducAÇÃO Domiciliar - Direito Já" caracterizam-se como empresários e famílias empreendedoras que comercializam conhecimento e que estabelecem, em torno da defesa pela 
A defesa pela "liberdade de escolha" fortalecendo uma rede empresarial: o homeschooling brasileiro

liberdade de escolha sobre como educar seus filhos, a busca pela concretização de um projeto societário excludente, não tão evidente.

Destarte, cumpre observarmos quem são os parceiros da campanha "EducAÇÃO Domiciliar - Direito Já" e os produtos que oferecem em suas plataformas digitais, de modo a vislumbrarmos a emergência de um nicho mercantil bem estruturado em torno de um intercâmbio entre empreendedores da ED que fornece desde cursos a certificações via web, conforme explicitaremos a seguir.

\section{Os apoiadores da "EducAÇÃO Domiciliar - Direito Já": a defesa de uma liberdade ou de um nicho mercantil?}

A campanha "EducAÇÃO Domiciliar - Direito Já", coordenada pela ANED, conta atualmente com 19 parceiros, entre instituições e famílias homeschoolers. O site na qual suas atividades estão concentradas foi o primeiro contexto virtual a ser focalizado nesta investigação. Na sequência, ao observarmos a indicação quanto aos parceiros que se uniram pela causa, buscamos informações referentes a eles, em seus próprios sites e/ou redes sociais. A análise deu-se a partir da aproximação discursiva que percebemos entre eles, mas também no que se refere aos temas abordados e às imagens reproduzidas, uma vez que o apelo visual dos sites é bastante relevante, incluindo fotografias de seus fundadores e colaboradores, o que nos auxiliou na identificação do intercâmbio profissional em diferentes plataformas.

Cumpre salientarmos que nossa concepção acerca do estabelecimento de uma rede empresarial com enfoque na defesa do homeschooling a partir do engajamento na campanha "EducAÇÃO Domiciliar - Direito Já" encontra esteio na perspectiva de Casanova e Ferreira (2020, p. 4) que, ao analisarem os discursos proferidos pela ANED, consideram que "[...] a modalidade torna-se um negócio rentável, pois concilia o desejo da família em realizar esses ideais e a inexperiência dos pais que precisam aprender a ensinar seus filhos". Ressaltamos que a observação dos sites dos apoiadores da campanha liderada pela ANED comprova tal assertiva, um vez que denotou a consolidação de um mercado de materiais didáticos e manuais que seguem a linha "como fazer".

No que se refere à campanha, esta se assenta em dois documentos norteadores: uma pauta de reivindicações e uma carta aberta à sociedade (ANED, 2019b, n.p.) A pauta de reivindicações volta-se aos pontos principais que deveriam, segundo a perspectiva desses sujeitos, orientar a regulamentação da ED no Brasil, a saber: garantia da liberdade educacional, igualdade de direitos entre estudantes domiciliares e escolares, simplificação do processo de cadastro de opção pela educação domiciliar, proteção às famílias que optarem pela educação domiciliar, flexibilidade do sistema avaliativo e certificador e proteção da autonomia familiar.

Já a carta aberta à sociedade apresenta, com maiores detalhes: os motivos que guiam a escolha dos pais e mães homeschoolers; o quanto eles são sabedores da responsabilidade que é educar seus filhos no ambiente doméstico; a escola como uma segunda opção social para a educação de crianças e jovens, pois a ED teria sido historicamente a primeira opção de escolarização; a discordância com relação ao processo de criminalização das famílias que optam pela educação domiciliar; e a necessidade de regulamentação legislativa da proposta. Conclamam, por fim, os interessados, para que se unam em prol da liberdade de escolha dos pais e das mães que optam por tal modalidade educativa.

Para além de tais materiais, o site apresenta mais informações sobre a ED de modo instrutivo, encaminhando o leitor aos itens de seu interesse com facilidade. $\mathrm{Na}$ aba denominada 
"mobilização", é possível acessar o layout dos itens de "divulgação" da campanha, como adesivos, placas, panfletos e camisetas (ANED, 2019b, n.p.) Ainda, nessa perspectiva, é inserida a temática referente à "Frente Parlamentar em defesa pelo Homeschooling", lançada em 2 de abril de 2019, em Brasilia/DF, composta por 240 deputados federais. Ressaltamos que se trata de Frente bastante representativa do ponto de vista quantitativo, partidário e geográfico, uma vez que reúne cerca de $50 \%$ dos deputados de 22 legendas, sendo pelo menos um parlamentar de cada estado brasileiro. Vasconcelos (2017) auxilia na compreensão de tamanho envolvimento parlamentar e estatal com a questão, alegando que "[...] para o Estado que tenta eliminar sua posição no tecido social, o movimento das famílias para assumir esse papel é visto e narrado positivamente como uma suposta liberdade de escolha, da qual não se pode privar os pais da opção sobre a educação dos filhos e filhas" (VASCONCELOS, 2017, p. 136).

Não obstante, o que importa, no âmbito desse trabalho, diz respeito ao conteúdo do item "apoiadores". Nesse link, estão presentes as logomarcas das instituições que formalizaram o apoio à campanha em foco e à temática da ED no Brasil. Um estudo acurado de cada uma delas denotou que, em sua maioria, elas mantêm uma perspectiva da educação com um direito privado, passível de produção intelectual em formato de produtos e acessível apenas a alguns, devido ao tipo de investimento que requerem. Observamos que as instituições e as famílias apoiadoras mantêm peculiaridades de atuação; todavia, o estabelecimento de uma campanha escancara e reforça a atuação destas em cooperação na defesa de um projeto maior. Castells (2005), ao abordar o tema referindo-se a redes de empresas, sugere que: "A empresa continua a ser uma unidade legal e uma unidade para acumulação de capital, mas a unidade operacional é a rede de negócios, aquilo a que eu chamo empresa em rede para enfatizar o facto de a rede se focar na concretização de um projecto" (CASTELLS, 2005, p. 21).

Ainda, em que pese a ANED salientar que não se trata de um movimento religioso conservador e que cerceie a atividade docente, a realidade encontrada nos sites das instituições que apoiam sua campanha é diversa. Tornou-se bastante evidente a presença de conhecimentos oriundos de vertentes religiosas fundamentalistas, negando a ciência do ponto de vista acadêmico. No que concerne a práticas conservadoras, é notório o papel diferenciado exercido pelas mães homeschoolers que, em sua maioria, optaram por cuidar do lar e de seus filhos. Já o cerceamento à atividade docente passa a se tornar mais claro a partir de editorais com chamadas voltadas aos "poderes ocultos do professor", por exemplo.

Optar pelo enfoque nas instituições que se identificam como parceiras em uma campanha pró-homeschooling tem também o objetivo de projetar luz a um perigo indicado anteriormente por Vasconcelos (2017):

[...] romper com a relação compulsória entre todos os sujeitos e a escola talvez contenha um risco maior do que aqueles já indicados pelo projeto neoliberal de reformas, uma vez que a aspirada liberdade de escolha pode deixar lacunas que, na desincumbência do Estado, permitirão a ascensão de outros espaços de profusão ideológica, espaços esses, talvez, mais difíceis de serem dissecados e analisados em suas fragilidades, do que a escola. (VASCONCELOS, 2017, p. 137).

Desse modo, passamos a evidenciar a identidade de cada parceiro, seja ele um sujeito individual ou coletivo, os produtos que oferecem e a vinculação existente entre eles ou não. A HSLDA (2019) figura como um parceiro central dessa campanha, sendo seus materiais traduzidos e amplamente utilizados no site, conforme já referido.

A “EDUCAR” (Educação Domiciliar Reformada) apresenta-se como o espaço dedicado para a troca de informações sobre a ED no Brasil. As últimas publicações são notícias compartilhadas de sites e redes sociais de outros parceiros, referendando a lógica da rede de atuação

Práxis Educativa, Ponta Grossa, v. 15, e2014819, p. 1-20, 2020

Disponível em: <http://www.revistas2.uepg.br/index.php/praxiseducativa> 
A defesa pela "liberdade de escolha" fortalecendo uma rede empresarial: o bomeschooling brasileiro

e, via de regra, possuem como legenda orientações religiosas, tais como: "Oremos pela ANED!". Os links disponíveis encontram-se descritos em inglês e remetem a sites norte-americanos, o que, segundo podemos interpretar, seleciona o público que tem condições culturais de acessá-lo (EDUCAR, 2019).

Do mesmo modo, o acesso ao site da "Classical Conversations", da Classical Christian Community, é seletivo, uma vez que seu conteúdo é apresentado apenas em inglês. Advoga por uma educação clássica, cristã e comunitária a partir de inscrições claramente religiosas, como "Conhecer a Deus e torná-lo conhecido". O método específico da "Classical Conservation" é produzido a partir de desafios gradativos apresentados ao estudante por meio de livros disponíveis para venda no próprio site (CLASSICAL CONVERSATIONS, 2019). Além disso, o Instituto de Otimização da Mente (IOM) é coordenado pelo Professor Juarez Lopes, que sugere ter desenvolvido um método peculiar voltado à leitura dinâmica. Para tanto, são ofertados, em sua plataforma virtual, cursos online e presenciais, bem como livros e dicas para otimizar os estudos e a memorização ${ }^{5}$. (IOM, 2019).

Os conteúdos do grupo "Homeschooling é Legal" apresentam uma tendência mais diretiva, no sentido de centrar o motivo da crise na educação na atividade docente. Exemplo disso é o texto que trata dos poderes ocultos do professor, de Leidiane Costa, segundo o qual os professores atuariam a partir do poder coercitivo que possuem. Ainda, o texto Entre armas e livros afirma que "[...] quando anos atrás, de uma forma muito sutil, o sistema educacional brasileiro foi sendo 'modificado', o objetivo era exatamente isso que hoje observamos: a anarquia e a indisciplina presentes em toda a sociedade", ao referir que a origem da violência social estaria na falta de educação das pessoas. Para Carlos Bachtold ${ }^{6}$, o autor do referido texto, o Estatuto da Criança e do Adolescente também teria influência negativa nesse processo, uma vez que "produz corruptos e bandidos", além de "filhos impedidos de serem castigados pelos pais, para serem mortos pelas milícias". Em uma das redes sociais do grupo, os links compartilhados remetem a outros parceiros da campanha, como, por exemplo, a ANED, o Instituto Angelicum, a Conecte HS, a ANDAPEF e a Classical Conversation (HOMESCHOOLING É LEGAL, 2019).

O Instituto Angelicum ${ }^{7}$ (2019) produz material nas áreas de linguagens e cultura clássica. Em sua página, chama atenção o link que direciona o leitor ao site de outro parceiro, a Conecte HS, que será devidamente apresentada posteriormente. Retomando, o Angelicum advoga pelo ensino do autoditatismo. Logo, em sua plataforma, um mesmo "docente autodidata" é responsável pelos cursos de italiano, inglês, francês, grego, latim para crianças e latim clássico. Ainda, surge entre seus colaboradores, um outro conhecido sujeito individual que atua na causa pró-homeschooling: o Professor Juarez, do IOM, nessa oportunidade atuando como facilitador do "Programa Fábrica de Leitores".

A Conecte HS (2019, n.p.) autointitula-se uma "[...] joint venture de empreendedores comprometidos com a excelência em educação" e oferece como principal serviço um selo de qualidade dos produtos oferecidos por suas "empresas associadas e produtores" a baixos custos. Desse modo, certifica a qualidade e reúne, em seu site, todos os produtos dos seguintes parceiros da ANED: Instituto Angelicum, Simeduc, Intesi, IOM e Fábrica de Leitores. De acordo com as

\footnotetext{
${ }^{5} \mathrm{Na}$ loja virtual do IOM, o livro mais barato custa $\mathrm{R} \$ 29,90$, enquanto os cursos variam entre $\mathrm{R} \$ 640$ e $\mathrm{R} \$ 1.257$, a depender da modalidade e da temática.

${ }^{6}$ Leidiane Costa e Carlos Bachtold também figuram como colaboradores da Coop Brasil, produzindo editoriais para publicação em seu site (COOP BRASIL, 2019).

${ }^{7} \mathrm{Na}$ plataforma EaD, é possível verificar os custos dos cursos ofertados. Há uma gama de planos a serem escolhidos, desde qualificações como "prata" até "passaporte mega, blaster, ultra transformador" (grifo nosso), variando entre si tanto no que diz respeito aos valores de investimento quanto à quantidade de cursos a que permitem o acesso. Por exemplo, um módulo do curso de “Latim para crianças" custa $\mathbf{R}$ \$600. Já um curso de “Inglês Completo" custa R $\$ 2.700$.
}

Práxis Educativa, Ponta Grossa, v. 15, e2014819, p. 1-20, 2020 Disponível em: <http://www.revistas2.uepg.br/index.php/praxiseducativa> 
informações disponíveis, a equipe da Conecte HS é composta pelas mães educadoras Silvaleide Rocha, Gaba Costa e Geovania Porto. O SIMEDUC (2019), por exemplo, trata-se de um simpósio online que versa sobre a ED e via de regra é certificado pela Conecte HS.

O Instituto de Estudos Independentes (INTESI), presidido pela Mestre em Políticas Públicas e Gestão da Educação Básica, pela Universidade de Brasília (UNB), Silvaleide de Souza Martins Rocha, também colaboradora do Conecte HS, consiste em uma associação de pesquisadores cristãos, professores e profissionais liberais do campo do Direito. Nessa Associação, os associados visam maior e mais profícuo diálogo entre universidade e igreja de modo a manter valores morais, éticos e espirituais (INTESI, 2019).

A Família de Trigo (2019) é composta por um casal homeschooler que oferece orientações, editoriais e materiais didáticos em uma plataforma digital na internet. Nela, é possível encontrar produtos voltados à alfabetização, ao letramento e à iniciação matemática de jovens crianças. As novidades desse site ficam por conta do clube de leitura, organizado para a troca de experiências em torno de determinados livros pré-estabelecidos, e do aplicativo de smartphone com links para famílias que pretendem aderir à ED. Nele, serão encontradas dicas e assessoria online 24 horas por dia. Ainda são disponibilizadas lives em plataformas de vídeo demonstrando os produtos e a forma indicada de utilização. Houve novamente a percepção quanto à colaboração de indivíduos que atuam em outras instituições, tais como o Professor autodidata do Instituto Angelicum. Como argumentos que fundamentam a adoção dessa modalidade educativa pelo casal, encontram-se a fuga de contextos escolares violentos, a possibilidade de adequação dessa a qualquer tipo de família e a economia estatal frente à responsabilização da família pela educação dos filhos.

A Fábrica de Leitores (2019) trata-se de um projeto de leitura desenvolvido experimentalmente em uma escola pública. Devido ao êxito alcançado, passou a ser replicado, de forma privada, por sua idealizadora Lissandra Lopes de Oliveira, que atua também como Diretora Administrativa no Instituto Angelicum e colaboradora no IOM.

O site Aprender em Família (2019, n.p.) também oferta materiais didáticos para o desenvolvimento da ED por famílias que possuem renda considerável, uma vez que se trata de acesso restrito, liberado mediante o pagamento de cada módulo adquirido. Um dos depoimentos de uma mãe educadora descreve que o método de caligrafia fez muito sucesso com seus filhos, a ponto de ela utilizar a mesma metodologia com as "crianças da congregação da igreja", reforçando a vinculação entre o homeschooling e uma perspectiva religiosa. Salientamos que não se trata de um pressuposto da modalidade educativa; entretanto, é comum que seus adeptos tenham hábitos cristãos, segundo uma orientação protestante.

Nesse sentido, é perceptível a maior aproximação de instituições voltadas aos valores familiares, como a "Juntos pela Vida", que claramente se trata de instituição contra o aborto, dada sua logomarca ser um feto, e a Homefeltron (2019, n.p.), que advoga pela manutenção e pelo fortalecimento de conhecimentos passados de geração a geração. Também, sem fins lucrativos e com caráter assistencialista, apresenta-se a organização social Amparo International (2019), que auxilia jovens em situação de vulnerabilidade social em áreas como educação, esporte e saúde.

A Associação de criação mais recente é a Associação Nacional de Defesa e Apoio aos pais na educação dos filhos (ANDAPEF), constituída a partir de encontros presenciais e virtuais de cristãos de diferentes igrejas evangélicas com a finalidade de discutir a ED. Além disso, produzem material e orientações para as famílias que pretendem acompanhar e zelar pela educação de seus

\footnotetext{
${ }^{8}$ O grupo "Juntos pela Vida" não possui site; entretanto, focalizamos suas redes sociais, nas quais a logomarca é produzida a partir de um feto e a foto principal do grupo é produzida junto ao altar de uma igreja.
} 
A defesa pela "liberdade de escolha" fortalecendo uma rede empresarial: o homeschooling brasileiro

filhos, seja em casa ou na escola. Os cursos ofertados pela instituição vão desde "Como vencer a depressão", passando por temas como "Introdução à filosofia da educação", "Da pedagogia científica ao emburrecimento global", "Trivium para iniciantes" e "Programa de leitura para crianças - 0 a 3 anos". Na loja da Associação, estão disponíveis, entre outros, o E-book (grátis) Devocional A Igreja no Lar, de vários autores, assim como outros livros para a venda, como Componentes Essenciais da Formação do Cristão Educador (R \$30,00), ComV ocação Básico II e III (13 e 14/12) (R\$300,00), além de algumas cartilhas, por exemplo, de "como fazer" a ímãs de propaganda da ANDAPEF (R \$ 5,00), Kit de Natal - Essencial ANDAPEF (R \$55,00) (ANDAPEF, 2019, n.p.).

O site da EDUCALAR (Educação Domiciliar) ${ }^{9}$ é um dos mais completos, possui desde produtos pedagógicos, como material dourado, a jogos, assessoria, vídeos e materiais didáticos. Tais serviços estão incluídos na assinatura de pacotes ofertados na loja do site, assim como materiais de divulgação e utilização individual. Visando uma produção discursiva favorável à ED, utiliza-se de notícias veiculadas em canais de comunicação diversos, sobre situações de violência que se deram em diferentes espaços escolares, além de reproduzir o embate atual criado em torno de questões como a ideologia de gênero, o feminismo e o aborto. Como diferencial, a plataforma reforça o desconto em diversos produtos, incluindo o "Material Mackenzie" (EDUCALAR, 2019, n.p.).

Com o crescimento das discussões em torno do que se pretende uma política, percebe-se de igual modo a efervescência de encontros presenciais em várias regiões do Brasil. Parece-nos evidente que há o estabelecimento de uma rede empresarial que atua a partir da colaboração de sujeitos individuais e coletivos em diferentes plataformas virtuais, conforme pretendemos problematizar na seção seguinte. Desse modo, consideramos que resta configurado o caráter empresarial que vem se consolidando conjuntamente à política de educação domiciliar no Brasil. A retórica do movimento em prol do direito de escolha das famílias homeschoolers, na verdade, mascara o empreendimento de especialistas e pais e mães que aderiram à ED e comercializam suas metodologias conforme o sucesso que conseguem atingir.

\section{A rede empresarial estabelecida em torno da Campanha "EducAÇÃO DOMICILIAR - Direito Já”}

De acordo com os registros obtidos nas plataformas digitais de cada um dos parceiros da ANED em prol da Campanha "EducAÇÃO DOMICILIAR - Direito Já", foi possível percebermos que diversas instituições e colaboradores vêm atuando de modo transversal e cooperativo, instituindo um verdadeiro monopólio acerca do conteúdo da ED no país.

Para Castells (2005), é latente que determinados campos da sociedade se sirvam da perspectiva de rede para estabelecerem melhores condições de desenvolvimento, exemplo disso seria a economia. Ao analisar a realidade americana, europeia e japonesa, o autor afirma que, desde a adoção da economia em rede, as taxas de crescimento da produtividade sofreram considerável elevação. Em consonância com o autor, considerando a realidade aqui observada, podemos inferir que a reunião dos parceiros, o estabelecimento de uma rede em torno de uma campanha que defende a legalização da ED, assim como a colaboração entre eles em suas plataformas digitais tende a alavancar os negócios que gerenciam, bem como pode inaugurar uma concepção política de educação diversa da constitucionalmente vigente em nossa sociedade. Assim, compreendemos que a proposta de ED totalmente sem regulação estatal evidencia a privatização do direito subjetivo à educação. Isso privilegia aqueles que financeiramente possuem maior capacidade de acesso aos

\footnotetext{
9 A assinatura dos pacotes ofertados no site tem o custo mínimo de $\mathrm{R} \$ 147,00$ por mês. A assinatura "Premium" direciona os contratantes a uma plataforma de acesso restrito.
} 
produtos e serviços amplamente comercializados pela rede empresarial já estabelecida e consolidada.

Não olvidamos, contudo, que seja o neoliberalismo o responsável pela inauguração do discurso que propaga a crise da educação, visando à inserção das lógicas de padronização e de controle; desse modo, passa a significar a educação pública como ineficaz, advogando por sua privatização a partir da livre concorrência orientada pelo mercado.

Por essa óptica, Freitas (2018) alega que a orientação neoliberal para o campo educativo inaugura, como vimos, um "livre mercado educacional". Todavia, os achados desta investigação vão além e demonstram que também se estabelece nele uma espécie de rede empresarial de colaboração e de produção didática que tem fortalecido a imagem de alguns atores como os sujeitos centrais da prática homeschooler no Brasil. Isso pode denotar o domínio de um nicho mercantil rentável por tais sujeitos em um curto espaço de tempo ${ }^{10}$. Para além disso, mantém-se, também, a conveniência de observarmos, assim como o autor, que "[...] o controle do processo educativo da juventude instala a hegemonia das ideias neoliberais" (FREITAS, 2018, p. 55), incluindo as que estabelecem a meritocracia, o cerceamento ao trabalho docente, a ausência da diversidade e de perspectivas sociais críticas no bojo das políticas educativas. Desse modo, compreendemos que tais prerrogativas pautam a ação das instituições focalizadas neste artigo.

Assim sendo, a Figura 1 a seguir retrata os apoiadores da campanha brasileira "EducAÇÃO Domiciliar - Direito Já", bem como alguns sujeitos que individualmente atuam em mais de uma organização social em prol da ED, produzindo e comercializando serviços às famílias homeschoolers. Pretendemos, desse modo, evidenciar a constituição de uma rede empresarial que em pouco tempo se estabelece e se consolida como referência na comercialização de materiais didáticos e no direcionamento da perspectiva pedagógica adotada pelos adeptos da ED no Brasil.

\footnotetext{
${ }^{10}$ De modo semelhante, Christian Laval (2004, p. XVIII) desenvolve uma analítica a respeito da situação do ensino público francês frente ao neoliberalismo alertando que observar "[...] as mutações escolares fornece argumentos sólidos à tese da desescolarização, cuja tendência é para uma pedagogização generalizada das relações sociais”. Para o autor, "[...] com a universalização da conexão mercantil dos indivíduos, parece chegada a época de um enfraquecimento das formas institucionais que acompanhavam a construção dos espaços públicos e dos Estados-Nações” (LAVAL, 2004, p.4); por conseguinte, estamos diante do processo de declínio da instituição escolar devido aos parâmetros políticoeconômicos impostos pelo neoliberalismo.
} 
Figura 1 - Apoiadores da Campanha "EducAÇÃO DOMICILIAR - Direito Já"

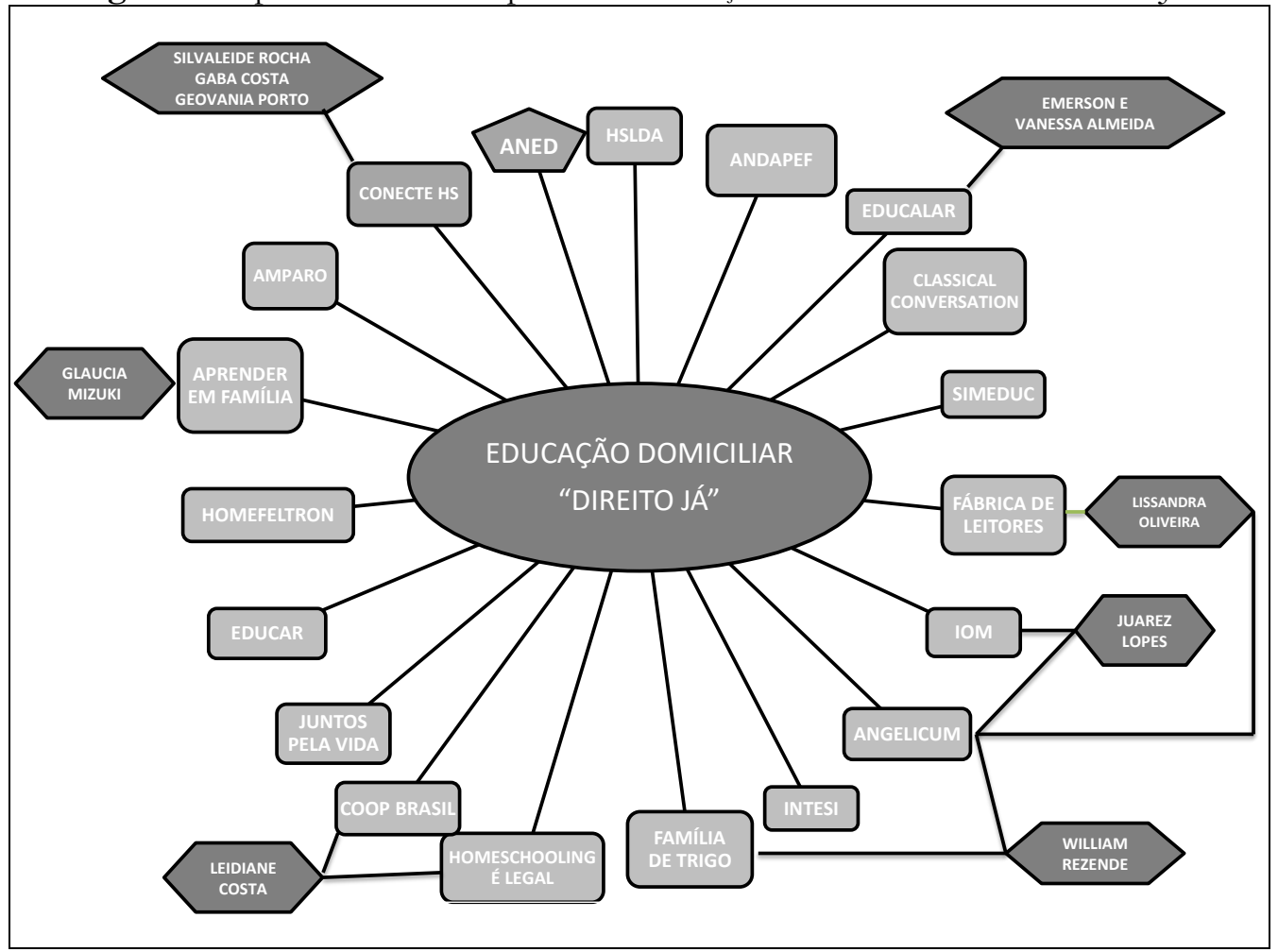

Fonte: Elaborada pelas autoras.

$\mathrm{Na}$ Figura 1, as instituições parceiras da Campanha são representadas nos retângulos. Acima e à esquerda delas, apresenta-se a ANED como organização diferenciada por meio de um pentágono. Imediatamente à sua esquerda, encontra-se a Conecte HS, relevante sujeito coletivo que vem desenvolvendo a certificação de cursos executados por várias instituições representadas nessa figura. Por fim, nos hexágonos, figuram os sujeitos individuais que, por vezes, se relacionam com mais de uma instituição, idealizando, coordenando ou produzindo materiais didáticos, editoriais ou mesmo participações especiais em congressos, seminários e audiências públicas.

A atuação das instituições em rede, assim como a influência individual que alguns sujeitos possuem com relação à materialização da política, parecem centrais em se tratando da face das definições que ela assumirá. Com semelhante relevância, entendemos urgente refletir sobre a concepção de Estado que essa modalidade educativa produzirá, uma vez que esses sujeitos se apresentam como as referências do campo, vinculados principalmente com a instituição protagonista da ED no Brasil, a ANED. Ainda, em estudo sobre o tema da ED, Barbosa e Oliveira (2017) assinalam que a concepção de cidadania que pretendemos construir no Brasil está em jogo, a partir de propostas diametralmente opostas. Afinal, considerando os argumentos dos autores, que tipo de cidadania queremos?

[...] uma cidadania mais preocupada com a manutenção dos direitos individuais, sobrepondo-os aos demais que, em decorrência, acolheriam a primazia das opções individuais e domésticas, ou uma cidadania mais articulada com os espaços coletivos e republicanos, nos moldes da educação escolar compulsória. (BARBOSA; OLIVEIRA, 2017, p. 20). 


\section{Considerações}

Neste artigo, a partir da análise das plataformas digitais dos apoiadores da campanha brasileira "EducAÇÃO Domiciliar - Direito Já", liderada pela ANED, identificamos quem são os seus apoiadores, os tipos de serviços que oferecem à população e como se dão suas relações na rede que constituíram. Observamos o fortalecimento da prática homeschool por meio da cooperação ativa de sujeitos individuais e coletivos em diferentes instituições, assim como a atuação de forma complementar como quando ofertam um curso em uma determinada plataforma e a certificação deste é emitida e/ou validada em outra. Torna-se, desse modo, perceptível a relação estabelecida entre estes sujeitos, consolidando um discurso que materializa uma política privada ofertada por eles próprios. A financeirização da proposta dá o tom mercantil à rede empresarial estabelecida.

$\mathrm{Na}$ análise empreendida, percebemos que os parceiros publicizam a rede ao participarem da campanha liderada pela ANED; todavia, a análise de suas plataformas digitais possibilita a compreensão de que essa rede já estaria fortalecida a partir da recorrente colaboração entre seus principais atores. Percebemos a consolidação de uma grande equipe pedagógica autodidata coesa, estruturando diferentes entidades, mas atuando em conjunto na defesa da modalidade educativa e do direito de escolha dos pais, que consequentemente lhes garantirá a demanda do serviço que já tem para oferecer.

Desse modo, a defesa de total liberdade para os pais, a fim de poderem decidir educar seus filhos em casa, os discursos de restrições à docência e à escolarização, além de motivações de base religiosa e financeira, inclusive com oferta de produtos e serviços a preços pouco acessíveis, ensejaram o exame do caráter seletivo da proposta de desenvolvimento da modalidade de Educação Domiciliar em nosso país. Isso reforça que se trata de uma política com viés neoliberal, neoconservador, segregacionista, consequentemente anticonstitucional.

A esse cenário podemos agregar o indicativo de que a profusão da referida rede em muito se deve à evolução tecnológica, que, no contexto global no qual nos inserimos, viabiliza a adoção de práticas internacionais, inclusive no campo educacional. Resta clara, na análise empreendida, o respaldo que a proposta de ED brasileira vislumbra em práticas norte-americanas, reforçando o autodidatismo e o acesso restrito a materiais produzidos de modo autoinstrutivo.

Em especial na conjuntura brasileira, o espectro dessa política potencializa uma corrida desleal em se tratando do acesso a formas de aquisição de capital cultural. Reforça, de tal modo, em nossa sociedade, o valor reconhecidamente neoliberal da meritocracia, subjugando preceitos constitucionais como os da dignidade da pessoa e do direito subjetivo à educação. Nesse sentido, o fato assume especial relevância quando problematizados, especialmente, o direito à educação e a obrigatoriedade da Educação Básica a todos os brasileiros, cuja conquista se encontra inscrita na Constituição Federal de 1988 e na atual Lei de Diretrizes e Bases da Educação Nacional.

Por fim, consideramos relevante ainda acentuar que a problematização aqui apresentada reveste o sutil, porém efetivo, ataque à educação pública brasileira. A privatização do contexto educacional, traduzida em ações desenvolvidas pelas famílias empreendedoras sob os seus auspícios, reforça as diferenças existentes entre os sujeitos, inaugurando um cenário de competição orientado por aspectos meritocráticos. Compreendemos, nessa perspectiva, que as discrepâncias, sobretudo as de cunho social, influenciadas pela concepção estatal difundida pela orientação político-econômica neoliberal e pelos ditames neoconservadores da extrema direita, ao serem potencializadas pela educação domiciliar, afetam diretamente a consolidação de uma sociedade democrática, justa, harmônica e igualitária. 


\section{Referências}

AMPARO INTERNATIONAL. Organização não governamental Amparo International. Home. Disponível em: <http://amparointernational.com/>. Acesso em: 30 jun. 2019.

ANDAPEF. Associação Nacional de Defesa e Apoio aos pais na educação dos filhos. Sobre. 2019. Disponível em: <https://andapef.org/sobre/>. Acesso em: 30 jun. 2019.

ANED. Associação Nacional de Educação Domiciliar. Breve Histórico da ANED. 2019a. Disponível em: <https://www.aned.org.br/historico-completo>. Acesso em: 18 dez. 2019.

ANED. Associação Nacional de Educação Domiciliar. EducacAÇÃo Domiciliar - Direito Já. 2019b. Disponível em: <https://www.direitoja.aned.org.br/divulgacao>. Acesso em: 30 jun. 2019.

ANED. Associação Nacional de Educação Domiciliar. Quem somos. 2019c. Disponível em: <https://www.aned.org.br/historico-completo>. Acesso em: 18 dez. 2019.

ANED. Associação Nacional de Educação Domiciliar. Histórico da ED nos três poderes: Legislativo. 2019d. Disponível em: <https://www.aned.org.br/legislativo>. Acesso em: 30 jun. 2019.

ANED. Associação Nacional de Educação Domiciliar. Histórico da ED nos três poderes: Judiciário. 2019e. Disponível em: <https://www.aned.org.br/judiciario>. Acesso em: 30 jun. 2019.

ANED. Associação Nacional de Educação Domiciliar. ED no Mundo. 2019f. Disponível em: <https://www.aned.org.br/conheca/ed-no-mundo>. Acesso em: 30 jun. 2019.

ANED. Associação Nacional de Educação Domiciliar. Histórico da ED nos três poderes: Executivo. 2019g. Disponível em: <https://www.aned.org.br/executivo>. Acesso em: 30 jun. 2019.

ANED. Associação Nacional de Educação Domiciliar. Associar-se. 2019h. Disponível em: <https://www.aned.org.br/participe/associar-se>. Acesso em: 30 jun. 2019.

ANED. Associação Nacional de Educação Domiciliar. Por que associar-se. 2019i. Disponível em: <https://www.aned.org.br/sobre-nos/por-que-associar-se>. Acesso em: 30 jun. 2019.

ANED. Associação Nacional de Educação Domiciliar. Entenda sobre "Educação Domiciliar". 2019j. Disponível em: < https://www.aned.org.br/conheca/perguntas-e-respostas>. Acesso em: 30 jun. 2019.

APRENDER EM FAMÍLIA. Venha aprender em família. Home. 2019. Disponível em: <https://aprenderemfamilia.maestrus.com/home/>. Acesso em: 30 jun. 2019.

BARBOSA, L. M. R.; OLIVEIRA, R. L. P. de. Apresentação do Dossiê: Homeschooling e o Direito à Educação. Revista Pro-Prosições, v. 28, n. 2, p. 15-20, mai./ago. 2017. DOI: https://doi.org/10.1590/1980-6248-2017-0121

BRASIL. [Constituição (1988)]. Constituição da República Federativa do Brasil. Brasília, DF: Senado, 1988. 
CASANOVA, L. V.; FERREIRA, V. S. Os discursos da Associação Nacional de Educação Domiciliar no Brasil. Práxis Educativa, Ponta Grossa, v. 15, p. 1-17, 2020. DOI: https://doi.org/10.5212/PraxEduc.v.15.14771.025

CASTELLS, M. A sociedade em rede: do conhecimento à política. In: CASTELLS, M.; CARDOSO, G. Debates da Presidência da República: A sociedade em rede - do conhecimento à acção política. Lisboa: Imprensa Nacional - Casa da Moeda, 2005. p. 17-30.

CLASSICAL CONVERSATION. Classical Christian Community. 2019. Disponível em: <https://www.classicalconversations.com/>. Acesso em: 30 de jun. 2019.

CONECTE HS. Quem somos. 2019. Disponível em: <https://institutoangelicum.com.br/conecte-hs/>. Acesso em: 30 jun. 2019.

COOP BRASIL. Juntos pelo homeschooling. 2019. Disponível em:<www.coopbrasil.org>. Acesso em: 30 jun. 2019.

CURY, C. R. J. A educação básica como direito. Cadernos de Pesquisa, São Paulo, v. 38, n. 134, p. 293-303, maio/ago. 2008. DOI: https://doi.org/10.1590/S0100-15742008000200002

CURY, C. R. J. Sentidos da Educação na Constituição Federal de 1988. Revista Brasileira de Política e Administração da Educação, v. 29, n. 2, p. 195-206, maio/ago. 2013. DOI: https://doi.org/10.21573/vol29n22013.43518

CURY, C. R. J. Homeschooling ou Educação no lar. Educação em Revista, Belo Horizonte, v. 35, p. 1-8, 2019. DOI: https://doi.org/10.1590/0102-4698219798

EDUCALAR. Educação Domiciliar. Quem somos. 2019. Disponível em: $<$ https://educalar.com.br/>. Acesso em: 30 jun. 2019.

EDUCAR. Educação domiciliar reformada. 2019. Disponível em: www.educacaodomiciliar.com. Acesso em: 30 jun. 2019.

FÁBRICA DE LEITORES. Página Inicial. 2019. Disponível em: <https://www.fabricadeleitores.com.br/>. Acesso em: 30 jun. 2019.

FAMÍLIA DE TRIGO. Família de trigo - Educação domiciliar no dia a dia. Página Inicial. 2019. Disponível em: <https://www.familiadetrigo.com.br/>. Acesso em: 30 jun. 2019.

FREITAS, L. C. de. A reforma empresarial da educação: nova direita, velhas ideias. São Paulo: Expressão Popular, 2018.

GAITHER, M. Homeschool: an American history. New York, NY: Palgrave Macmillan, 2008.

GAITHER, M. Homeschool: an American history. 2. ed. New York, NY: Palgrave Macmillan, 2017.

HAMLIN, D. Do Homeschooled students lack opportunities to acquire cultural capital? evidence from a nationally representative survey of American households. Peabody Journal of Education, v. 94, n. 3, p. 312-327, 2019. DOI: https://doi.org/10.1080/0161956X.2019.1617582

HOMEFELTRON. Bem vindo a homefeltron. 2019. Disponível em: $<$ https://homefeltron.com/>. Acesso em: 30 jun. 2019. 
A defesa pela "liberdade de escolha" fortalecendo uma rede empresarial: o homeschooling brasileiro

HOMESCOOLING É LEGAL. Sobre. 2019. Disponível em: <https://homeschoolingelegal.com.br/>. Acesso em: 30 jun. 2019.

HSLDA. Home School Legal Defense Association. 2019. Disponível em: <https://hslda.org/content/>. Acesso em: 30 jun. 2019.

INSTITUTO ANGELICUM. Instituto Angelicum. Home. 2019. Disponível em: <https://institutoangelicum.com.br/>. Acesso em: 30 jun. 2019.

INTESI. Instituto de Estudos Independentes. Quem somos. 2019. Disponível em: <https://www.institutointesi.com/>. Acesso em: 30 jun. 2019.

IOM. Instituto de Otimização da Mente. Página Inicial. 2019. Disponível em: <https://www.cursoiom.com.br/>. Acesso em: 30 jun. 2019.

LAVAL, C. A Escola não é uma empresa. O neo-liberalismo em ataque ao ensino público. Londrina: Editora Planta, 2004.

LIMA, P. V. de. Influências neoconservadoras na educação pública: sujeitos em relação. In: PERONI, V. M. V.; LIMA, P. V. de; KADER, C. R. (orgs.). Redefinições das fronteiras entre o público e o privado: implicações para a democratização da educação. São Leopoldo: Oikos, 2018. p. 125-131.

OLIVEIRA, R. L. P. de; BARBOSA, L. M. R. O neoliberalismo como um dos fundamentos da educação domiciliar. Pro-Prosições, Campinas, v. 28, n. 2, p. 193-212, maio/ago. 2017. DOI: https://doi.org/10.1590/1980-6248-2016-0097

PERONI, V. M. V. Implicações da relação público-privada para a democratização da educação. In: PERONI, V. M. V.; LIMA, P. V. de; KADER, C. R. (orgs.). Redefinições das fronteiras entre o público e o privado: implicações para a democratização da educação. São Leopoldo: Oikos, 2018. p. 93-104.

PERONI, V. M. V.; CAETANO, M. R.; LIMA, P. de. Reformas educacionais de hoje: as implicações para a democracia. Revista Retratos da Escola, Brasília, v. 11, n. 21, p. 415-432, jul./dez. 2017. DOI: http://dx.doi.org/10.22420/rde.v11i21.793

SIMEDUC. Simpósio online de educação domiciliar. 2019. Disponível em: <https://simeduc.com.br/>. Acesso em: 30 jun. 2019.

VASCONCELOS, M. C. C. Educação na casa: perspectivas de desescolarização ou liberdade de escolha? Pro-Prosições, Campinas, v. 28, n. 2, p. 122-140, maio/ago. 2017. DOI: https://doi.org/10.1590/1980-6248-2015-0172

VASCONCELOS, M. C. C.; BOTO, C. A educação domiciliar como alternativa a ser interrogada: problema e propostas. Práxis Educativa, Ponta Grossa, v. 15, p. 1-21, 2020. DOI: https://doi.org/10.5212/PraxEduc.v15.14654.019

Recebido em 24/02/2020

Versão corrigida recebida em 29/03/2020

Aceito em 30/03/2020

Publicado online em 04/04/2020

Práxis Educativa, Ponta Grossa, v. 15, e2014819, p. 1-20, 2020 